Publisher: Taylor \& Francis

Journal: Archives of Environmental \& Occupational Health

DOI: https://doi.org/10.1080/19338244.2018.1453774

\title{
Environmental factors and suicide in Australian farmers: A qualitative study
}

Meg Perceval $^{1}$, Kairi Kõlves ${ }^{1}$, Victoria Ross ${ }^{1}$, Prasuna Reddy ${ }^{2,3}$, Diego De Leo ${ }^{1}$

${ }^{1}$ Australian Institute for Suicide Research and Prevention, National Centre of Excellence in Suicide

Prevention, World Health Organization Collaborating Centre for Pesearch and Training in Suicide

Prevention, Griffith University, Australia

${ }^{2}$ Faculty of Health, University of Technology Sydney, Ausiralià

${ }^{3}$ Institute of Psychiatry, Psychology and Neuroscience, KAng's College London, UK

\section{Corresponding author:}

Kairi Kõlves

Australian Institute for Suicide Research and Prevention

176 Messines Ridge Road

Mt (rravatt eampus, Griffith University QLD 4122

Phore- 61737353380 Fax - 61737353450

Email - k.kolves@griffith.edu.au

Running head: Environmental factors related to suicide in farmers 


\section{ABSTRACT}

Farmers and farm workers have been recognised as a group at high risk of suicide in Australia. This study aims to identify and better understand environmental factors associated with suicide among Australian farmers and farm workers. Qualitative analysis was undertaken in accordance with the Consolidated Criteria for Reporting Qualitative Research. Male and female focus groups were conducted separately with people who lived or worked on a farm in six farming communities. Qualitative analyses showed that a number of environmental influences may contribute to the increased risk of suicide: extreme climatic events; isolation; service availability; access to, and frequent use of firearms; death and suffering of animals; government and legislation; technology; and property values. Both the physical and socio-cultural environments in which armers operate appear to contribute to farmer suicide and need to be considered in suicioe prevention.

Key words: environmental factors, farmer, suicide suidide prevention 


\section{Introduction}

Within rural populations, farmers have been identified as having higher rates of suicide in numerous countries across the world. ${ }^{1}$ In a systematic review and meta-analysis, Milner et al, ${ }^{2}$ found a link between occupation and suicide risk, including increased risk for farmers and agricultural workers. In Australia, farmers and people who live in more remote communities are at high risk of suicide..4 Several studies have investigated individual suicide risk factors for farmers such as mental illiness, 5 and other factors specific to farming such as the overlap of workplace and home, issolation and working alone, and intergenerational business partnerships. ${ }^{6,7}$ Only a few studies have in: vestigated external factors such as the impact of climatic events and economic impacts. 8,9 Despite the well documented disparity in farmer suicide compared to many other occupations in Australia, many researchers agree the reasons for this disparity remain poorly understood. ${ }^{10-12}$ Further qualitative research has been recommended to better understand the complex iriterplay of contributing factors ${ }^{10}$ so that targeted strategies can be designed and delivered is those most at risk, given demographic and geographical variation in farmer suicide mortality. 13,14

Suicidal behaviour is a complex inierplay of psychological, social, biological and contextual factors. The use of an ecological framework has been recommended, but not widely used in understanding suicidal behaviols. The World Health Organization ${ }^{15}$ uses an ecological framework to explain why some people are at higher risk of self-inflicted, interpersonal or collective violence, acknowledging the interaction of many factors at different levels. This framework delineates individual, relationship, community and societal levels. ${ }^{16}$ Stineman and Streim ${ }^{17}$ extended this work and proposed the biopsycho-ecological model. Highly interactive and multilevel functional hierarchies within this model acknowledge that illness may reside in the body or the mind, but that the environment may improve or exacerbate this with physical or social influences. ${ }^{17}$ The biopsycho-ecological model recognises the critical interface between the person and the environment, and how the physical environment may have facilitators or barriers which enhance integration or contribute to isolation. ${ }^{18}$ 
The current paper will address environmental factors, including both the physical and sociocultural environment, associated with the suicide of Australian farmers as perceived by farmers themselves.

\section{Methods}

Qualitative analysis was undertaken in accordance with the Consolidated Criteria for Reporting Qualitative Research (COREQ) checklist. ${ }^{19}$ The study was approved by the University of Neivcastle (H-2013-0009) and Griffith University's Human Research Ethics Committees (CT/1/04/12/SREC).

\section{Participants}

Focus groups were conducted in three sites in New Soun Wales (NSW) and three sites in Queensland (QLD). A purposive sampling framework was applied to recruit participants who lived and/or worked on farms. The sites in both States were selected to represent areas with a suicide rate equal to, above and below the State average and that were geographically diverse: remote, outer regional and inner regional. Rural agencies in each site with existing relationships with farmers sent out email invitations and study information through rural networks and agencies in the selected sites. In total, across both States, there were 30 male and 33 female participants. Focus groups were conducted separately for males and females secause heterogeneous gender groups may lead to female participants dominating discussion. Exısing literature and experience in rural communities on masculinity and males has found communication regarding personal and mental health issues more difficult for men compared with women. ${ }^{20}$ It was anticipated that both men and women would feel more able to discuss opinions openly in same-gender groups ${ }^{21}$. Venues were provided by rural networks in NSW, and in hired venues in QLD. A $\$ 50$ voucher was given to participants as reimbursement for travel costs. 
In NSW the groups each consisted of six men and six women across the three sites, with a total of 18 women and 18 men. In QLD, due to difficulties with recruitment, the groups ranged from 2 to 6 participants, and were supplemented with individual interviews, in some cases over the telephone. In total, 12 men and 15 women participated in QLD. Participants' ages across both sites ranged from early 20 s to mid-70s. Table 1 describes participants.

\section{Data collection}

The social constructivism tradition guided the research, with focus giouns designed so that researchers could learn about how participants perceive and understand the environment in which they live and work. ${ }^{22}$ The topic guide for the focus groups and interviews explored farmers' perceptions, knowledge and experiences of suicidal behaviour, and comprised 11 open-ended questions under the three broad topics of perceived ris factors, perceived protective factors and attitudes towards suicide (Appendix 1). Under these three topics, analysis showed three major themes emerged in relation to risk factors: Individual, social and environmental. The findings pertaining to individual risk factors as well as attitudes towards suicide have been previously reported ${ }^{23}$ and a further paper is underway on sociai risk factors, this study therefore focuses on environmental risk factors related to sizicide.

The NSW groups were facilitated by a female $\mathrm{PhD}$ student (MP) who worked in rural suicide prevention and lived and worked on a farm, and was known to some participants from one of the sites. The facilitator explained her background in farming and interest in the wellbeing of people living and working on farms. In QLD groups were facilitated by a female registered psychologist with a postgraduate qualification and a female consultant with $\mathrm{PhD}$ qualification (both previously unknown to participants). Participants were assured that they would be given access to follow-up mental health 
services if required. Focus groups and interviews ran for between one and three hours and were audio recorded and professionally transcribed.

\section{Data analysis}

A generic qualitative approach ${ }^{24}$ was conducted using inductive thematic analysis. Coding and theme development was directed by the content of the data. ${ }^{25}$ Transcripts were read by two authors, to familiarise themselves with the data and to generate initial codes and themes. Three authors decided on the final themes and identified connections between themes. Comprehensive analysis and review were conducted by one author, which involved extensive re-reading and close analysis of transcripts utilising NVivo software, and following the characteristics of qualitatve research described by Gibbs. ${ }^{26}$ Data remained coded under question topics, however nodes were created according to final themes. Validity of analysis was ensured via continual and on-geing discussions with at least one other author to allow for reassessment of themes, further interpretation of data and to gain consensus.

\section{Results}

Eight subthemes of envirormental faciors related to farmer suicide were identified. Some of these related to the impact of the physical environment on the farmer; others related to the sociocultural environment in which farmers are operating.

\section{Extreme climatic events}

The eifects of prolonged and severe drought on individuals, farming families and rural communities reliant on agricultural industry dominated focus group discussions in both QLD and NSW. Other adverse climatic events, such as floods, were also described as having considerable impact on all aspects of farming life. Adverse climatic conditions were described as leading to hopelessness and despair as farmers depicted "no win" situations, where despite their best efforts; they were left in dire 
hardship. This stress was described as affecting not only the individual farmer, but also all people involved in the business, family, and wider community, and as a contributor to some people contemplating suicide. Participants discussed how adverse climatic events impacting financial viability may lead to a sense of personal failure, which in turn may lead to risk of suicide for some.

M1: The pressure goes from the drought, the financial side of it, then the pressure goes across to the wife, the family, the wife leaves him or busts up and then the suicide happens.

M2: When you're under the stress of the drought and the financial... some just can't live with the stigma of going to lose their property and go.

\section{Isolation}

Geographical isolation was a major issue for the more remote communities. Lengthy distances to travel and lack of services including ambulance, police and primary health care were pronounced in some sites. In one group patticipants described travelling to the nearest capital city, over 700km away, in order to see a regular doctor. The isolation was often further complicated by poor access to telecommunications, such as mobile phone coverage and Internet availability. The groups described not only the hardshit of living in rural communities, but also the anxiety and sense of vulnerability that arose from being geographically isolated and far away from medical and emergency services. The isolating nature of farming itself and the many hours spent working alone were also discussed. Participants in a number of groups spoke about the combination of geographical and emotional isolation as a potential risk factor for suicide. 
M3: The main risk factor is isolation or even access to isolation. Because they are not going to suicide in front of someone... don't let them be isolated. That's a lot to do with farming... if there's someone around all the time they get less opportunity to be able to do it.

M4: I think the problem with those people who are contemplating suicide... the fact that we can be isolated... you can become anonymous if you want.

\section{Service availability}

With the exception of the larger regional sites in both states, lack of adequate services was a strong feature of all groups. Some sites had no doctor and many spoke of the transient nature of primary health and other workers in their geographically isolated rural conmunities, or the inadequacy of "fly in/fly out" services. Participants described how service providers who work in regional and remote areas often do so to meet professional service requirements; returning to work in the cities on completion of their service period. The desire for more permanent service providers and the opportunity to connect and build trusted elationships was highlighted during discussions. Face to face services, particularly with- someene who understood the difficulties of farming were consistently described as preferabie to telizphone or online services based in a major city (where the service provider was likely o have little understanding of the geographical location or particular issues affecting the farming community).

F1. What we miss out here is having a thread and a connection. So your police officer, your teacher, your principal, the people who can live in the community and work... you don't have any long-term connection with a doctor or any of those services because people come out here to "tick a box", do their stint... (and return to the cities). 
F2: I've tried (a helpline) and it didn't help us in our dire time when we really needed help... It wasn't a service that worked... it is very hard to access... the capacity of the person suffering to access that. So physical presence is really the only thing.

\section{Access to, and frequent use of, firearms}

There was considerable discussion relating to the access, familiarity with, and repetitive use of firearms throughout all groups and interviews. Firearms are an important fosi for Australian farmers for controlling pests such as kangaroos and wild pigs, and for euthanizing livestock suffering during drought and at other times. The frequent use of firearms was identified as unique to farming as an occupation, as was the relationship of firearms to farmer suicide. Participants generally considered that access to, and familiarity with firearms was a reason that farmers are at higher risk of suicide. One participant noted that he had known a number of male farmers who had died by suicide, and all had used a firearm as their suicide method. The lethality of firearms in combination with access and familiarity was highlighted; as yas the farmer's acquired capability to enact lethal self-harm through habituated daily activities within the rarming environment, such as the repeated use of firearms for pest control and euthanasia of anirnals.

M5: Inink that 's why rural suicide is probably a bit worse than anywhere else because we've got the artillery to ve it. You don't get a second chance when you start (firing) that around.

M3: That may be why suicide is at a higher rate in the country, because we do that (use firearms) on a daily basis anyway. It's an identified end to a problem for everything else. 


\section{Death and suffering of animals}

Closely linked to access and use of firearms, was the distress caused by the suffering of animals, particularly due to drought and climatic adversity. The need for the humane euthanasia of animals and repeated exposure to their death was a common theme in focus group discussions. This was particularly evident in the QLD groups where the combination of drought and inability to sell livestock or property left beef producers with starving cattle, which in many instances died. Participants in all of the groups, even in NSW where droughts had not been so severe, spoke of their distress in watching animals suffer, and the difficulty of having to euthanize them. Sorit of the males spoke of how they attempted to protect their wives and children from the death of stock during drought. Several male farmers agreed that when they were struggling mentally they would often ask their workers or neighbours to assist them in euthanizing animals, as they were concerned about the impact this was having on their mental wellbeing.

M6: When you get up in the morning and you've got to go out... and you're seeing all these dead animals consistently every day and havng to shoot the cows, shoot the calves every single day, no days off. This went on for nearly two years... it wears you down.

M7: I have a groa' mate of mine (who told me) "I haven't taken my wife out into the paddock for more than a year .. because it's so bad and there's so much death". He said "I don't want her to see it... I'm struggling, to handle it myself."

\section{Government and legislation}

Government policy and legislation were generally described as being unhelpful to farmers and adding additional pressure. Examples predominantly focused on the Australian Federal Government's ban on 
live cattle export to Indonesia following images of cattle being mistreated in Indonesian slaughterhouses that appeared on national television. This ban particularly impacted northern QLD cattle farmers, who rely heavily on the live export trade. Other government policies discussed included changes to water licensing, and the extensive documentation required to obtain governmental grants or subsidies during times of hardship. In several focus groups, externai influences were raised, such as the presence or threat of coal seam gas on farming land, where it was argued fertile farming land and groundwater were at risk of being lost and/or irreparabiy darnaged as agricultural land turned to an industrial landscape. Another issue was the rise in foreign of corporate land ownership. Industry changes such as these were highlighted by participants as causing significant stress, which may be associated with farmer suicide. These external stressers were seen to add to what was already beyond the control of the farmer: an additional adversity that increased the burden of their business and daily stress. Participants also described teeling "let down" and unsupported by Government. There was a very strong sentiment that farmers were not valued by politicians and that decisions were often made in the capital cities by people who did not understand farming. The belief that farmers are not valued by the broader society appeared in conversations across groups and seemed to compound individual stressors and feelings of worthlessness, adding to the risk of suicide.

M8: I think therg is a yery real sense of helplessness or hopelessness (for farmers) when it comes to government legislation.

M9: I often feel overwhelmed... the documentation and the paperwork... there's all these legal protocols and things for us to follow, and every single thing you do (to obtain hardship assistance). 


\section{Technology}

Significant changes to traditional farming businesses and communities due to the advent of computer technology were highlighted across all groups, as was the impact of social media and techioingy on relationships. There was some consensus among participants that technology was detrasting irsm interpersonal relationships. Farmers described the increasing need for technology in an already overburdened work environment as stressful, as they perceived they did not have the time or skills to keep up. This was particularly relevant for older farmers. Technology in business was described as burdensome, adding extra work in an already "overloaded" environment. Similar to Government legislation, new technology was described as adding extra stress and workload in many instances. Whilst this theme was not spoken of in terms of a direct risk ior suicide, it did feature as a significant stressor relevant to the environment in which farmers were operating their businesses.

M10: Every time you turn the compuier on...there's something that you don't quite know how to do.

M11: Technology is gleat but it is just pressure, pressure, pressure on me all the time.

\section{Property Values}

Another theme that was related to farm financial viability and the impact of financial pressures on individuals, families and whole rural communities was that of property values. After experiencing somewhat of a "boom", property market values plummeted as a result of a combination of factors including the broader global financial crisis, prolonged drought, commodity price falls, and market shocks such as the live cattle export ban. This was described amongst groups as another reason 
farmers felt "trapped" with "no way out". Some farmers had borrowed money against inflated values and subsequently had huge equity reductions resulting in significant financial pressure. They described being in a helpless situation of not being able to sell their properties due to these factors, especially in the case of ongoing and severe drought.

F3: The property value's decreased 25 per cent or more. Your cattle prices - instead of a com being worth $\$ 1,000$, it was worth $\$ 250$. You have your bank manager there - they're not giving you any more money... and there's nothing you can do. You're stuck there. You can't really sell your property because who's going to buy it at the present moment.

M12: My grandfather raised and educated a whole family... and I can't even sell the place.

\section{Discussion}

Farmers are inextricably linked to their physical and sociocultural environment. Adverse environmental factors in coribination with unfavourable individual and social circumstances may lead to farmer suicides. Therefore the biopsycho-ecological model ${ }^{17}$ is a useful framework for understanding farner suicide. The current paper focussed on qualitative analysis of farmers' perceptions of envirenmental factors impacting on farmer suicides in Australia. We identified eight subthemes: extrenie climatic events; isolation; service availability; access to, and frequent use of, firearms, death and suffering of animals; government and legislation; technology; and property values.

In relation to climate, severe and ongoing drought was a major point of discussion in this study. Previous studies have considered the role drought plays in combining pressures which may 
accumulate and lead to hardship, distress and decreased mental health and wellbeing for farmers. ${ }^{8,27-29}$ Our findings indicated that drought and other extreme environmental events add physical, mental, financial, interpersonal and social strain to farming individuals, families and communities, which may increase risk for suicide.

In Australia, some studies have shown an increase in rural male suicide with increasing arought index that was not evident in females, ${ }^{30}$ while other studies have shown no association between drought and suicide rates. ${ }^{31}$ It appears that men may be more vulnerable to the impact of climatic and environmental pressures such as drought on mental health and suicide risk inan women, ${ }^{30,32}$ and rural dwellers more so than urban residents. ${ }^{33}$ Despite these mixed resultis, it is recommended that drought and other climatic and environmental factors are not dismissed as relevant to farmer suicide risk even if robust group data is not clear at this stage. ${ }^{31}$ The State of Queensland Agricultural Report ${ }^{34}$ suggests that drought and other environmental hardship are to be expected. There is therefore a need for improved ways to support farmers in managing these predicted hardships, and reducing the impact of environmental factors that may impact on farmer suicide.

Access to, and frequent use of firearms featured strongly in our study, and is a critical aspect of the farmers' working environment. One theory that is potentially relevant to how this translates to farmers' fsk so? sulcide is Joiner's interpersonal theory of suicide (IPT). ${ }^{35,36}$ The psychological aspects of "thwarted belongingness" and "perceived burdensomeness" in this theory links to the "Mesire" for suicide. ${ }^{35,36}$ Central to our findings on environmental influences on farmer suicide, we found this theory resonates strongly in terms of the farmers' "capability" for suicide. Farmers in our study referred to repeated exposure to pain, suffering and death of animals they care for, especially during environmental events such as drought. They also described extensive familiarity and frequent use of firearms. Limiting access to firearms, and indeed even the need for them, may be problematic, 
as they are a tool of trade for farmers. However, IPT could explain why farmers may be at increased risk of suicide, on account of their capability. ${ }^{35,36}$

Farming is, by its very nature, an isolated occupation. Participants described emotional isolation in a myriad of ways as compounding physical isolation. Lack of services and distances to services in addition to the sociocultural environment, is likely to impact help-seeking. ${ }^{1,37}$ Traditional masculine paradigms of farming in Australia may reinforce stigma that could increase both aversion to helpseeking and indirectly increase the risk for suicide. ${ }^{38}$ Fennell et al, ${ }^{39}$ comparing barriers to helpseeking for physical and mental health issues in rural South Australiars, fonind higher barriers for mental than physical health concerns. The need for control and self-reliance has been reported as a stronger barrier for farmers than non-farmers in seeking supnort for mental health problems in the same state. ${ }^{40}$ In NSW, Brew et al $(2016)^{41}$ reported tha $c$ ail farmers, regardless of rurality, were half as likely to visit a GP or mental health professional in the last 12 months compared to non-farm workers, but that remote farmers were more likely to be more isolated and have less access (structural barriers) to care. Farmers are more than three times as likeiy to die by suicide in QLD than in NSW. ${ }^{13}$ Overall, the reasons for increased rural suicide in Australia remain unclear. ${ }^{11}$ Whilst nothing stood out in our focus groups to clearly explain the higher rate of suicide in QLD farmers, perhaps geographical isolation is relevant, given the larger size of this state, and greater distances between farms and major centres. This prysical isolation may compound barriers to service utilisation within the sociocultural environment, making help seeking even less likely. A longitudinal cohort study in rural $\mathrm{NSW}^{41}$ found that remoteness was a significant factor. Remote farmers self-reported worse mental health and wellbeing than remote non-farm workers regardless of recent adverse life events, financial hardship or elimatic adversity. ${ }^{41}$ This compared to regional farmers, who did not differ from regional non-farm workers on either indice. ${ }^{41}$ Geographical isolation, combined with loneliness, withdrawal and the intrinsic isolation of farming as an occupation ${ }^{3,23}$ as well as sociocultural norms and attitudes ${ }^{28,40,41}$ may therefore be relevant to increased rates of farmer suicide. 
Impacts of government legislation, available services, technology, and property values in particular, arose as working environment elements contributing to farmers' stress. Others have found hopelessness regarding a lack of control over internal and external events (such as Government policy and bureaucracy) to be relevant to farmer suicide in Australia and other countries. ${ }^{3,23,28,42}$ The inneact of mining development on farmers' mental health due to competing land use, psychological stress and tensions within the community have also been reported. ${ }^{43}$ This information should provide useful guidance when considering future initiatives to improve farmer wellbeing and reduce suicide. Increased consultation with farmers in relation to changing and forming legisiation, for example, may be helpful. Improving telecommunication services in more remote areas, as well as education to improve farmers' efficient use of technology may assist. Farmers described a clear and strong preference for face-to-face services, with people who have an understanding of their local area, and farming in particular. This should be taken into account when planning health and mental health services for rural areas, as well as the need io link these services to those that the farmer is already familiar and confident with using, such as agricultural services. Given the impetus towards research for smart phone and app technolegy in ass sting mental health treatment, perhaps younger farmers, and those already familiar with using lechnology, who do have good Internet access, could benefit. Debt to equity ratios shouid be considered by financial institutions and governments alike in future planning to assisc farmets remain viable and for properties to stay within reach of family ownership.

\section{Limitations}

There were different facilitators in the two states and recruitment proved difficult in QLD due to fewer existing networks between researchers and farming communities. Data collection was staggered over time. Because of recruitment issues in QLD, some individual interviews were conducted, in some instances, over the telephone. Therefore the group dynamics were different with fewer participants, or non-existent in the case of individual interviews. Despite these recruitment variations, 
consistency was provided through the use of a topic guide, and participant responses could be grouped under congruous themes.

\section{Conclusion}

Whether it is the physical environment in which we work and live, or the environment that is created by social policy or specific external influences in which we operate, environmental factors impact on suicidal behaviour. This study aimed to identify and better understand environmental factors associated with suicide in Australian farmers and farm workers. We fourd extreme climatic events; isolation; service availability; access to, and frequent use of firearms, death and suffering of animals; government and legislation; technology; and property values as the main/environmental influences perceived by farmers to contribute to suicide risk. Both the physical and socio-cultural environments in which farmers operate appear to contribute to farmer syicide and need to be considered in future suicide prevention, alongside individual and socia elements. Our study offers new information by uncovering perceived risk factors for suicide drectly from farmers themselves, and suggests how, based on these findings, combining relevant theories, such as IPT, with the biopsycho-ecological model, may provide greater insight into both understanding and addressing farmer suicide. Farmer suicide prevention programs that address physical and social isolation, sociodemographic disadvantage, chailenge sociocultural norms, and take into account contextual environmental elements such as access to firearms and climate adversity are recommended. 


\section{References}

1. Hirsch J, Cukrowicz K. Suicide in rural areas: An updated review of the literature. J Rural Ment Health. 2014;38(2):65-78.

2. Milner A, Spittal M, Pirkis J, et al. Suicide by occupation: systematic review and metaanalysis. Br J Psychiatry. 2013;203(6):409-416.

3. Judd F, Jackson $\mathrm{H}$, Fraser $\mathrm{C}$, et al. Understanding suicide in Australian rarmers. Soc Psychiatry Psychiatr Epidemiol. 2006;41:1-10.

4. Page A, Fragar L. Suicide in Australian farming, 1988-1997. Australas Psychiatry. 2002;36(1):81-86.

5. Caldwell T, Jorm A, Dear K. Suicide and mental health in rural, remote and metropolitan areas in Australia. Med J Aust. 2004;181(7):10.

6. Hirsch J. A review of the literature on rural suicide: Risk and protective factors, incidence, and prevention. Crisis. 2006;27(4):189-199.

7. Handley T, Inder K, Kav-Lambkin F, et al. Contributors to suicidality in rural communities: Beyond the effects of depression. BMC Psychiatry. 2012;12(1):105.

8. Alston M. Rural male suicide in Australia. Soc Sci Med. 2012;74(4):515-522.

9. Byant 1, Garihham B. The fallen hero: masculinity, shame and farmer suicide in Australia. Geva' Place Cult. 2015;22(1):67-82.

10 Collins J, Ward B, Snow P, Kippen S, Judd F. Compositional, Contextual, and Collective Community Factors in Mental Health and Well-Being in Australian Rural Communities. Qual Health Res. 2017;27:677-687. 
11. Inder K, Handley T, Johnston A, et al. Determinants of suicidal ideation and suicide attempts: parallel cross-sectional analyses examining geographical location. BMC Psychiatry. 2014;14:208.

12. Judd F, Cooper A, Fraser C, Davis J. Rural suicide-people or place effects? Aust NZ J Psychiatry. 2006;40:208-216.

13. Arnautovska U, McPhedrana S, Kelly B, et al. Geographic variation in suicide rates lî Australian farmers: Why is the problem more frequent in Queensland than in New South Wales? Death Studies. 2016;40(6):367-372.

14. Authors

15. World Health Organization. Global campaign for violence prevention. http://www.who.int/violenceprevention/approash/ecology/en/ Accessed 12 Oct 2017

16. Krug E, Mercy J, Dahlberg L, et al. The world report on violence and health. Lancet. 2002;360(9339):1083-1088.

17. Stineman M, Streim J. The Biopsycho-ecological paradigm: A foundational theory for medicine. Am J Phys Mea Reh.abil. 2010;2(11):1035-1045.

18. Stineman, M. G., \& Qu, W. Untangling function: Measuring the severity, type and meaning of disabiities Europa Medicophysica, 2007; 43(4), 543-549.

19. Tong A, Sainsbury P, Craig J. Consolidated criteria for reporting qualitative research (CDFEQ): a 32-item checklist for interviews and focus groups. Int J Qual Health Care. 2007;19(6):349-357.

20. beyondblue, 2012: Men's Help Seeking Behaviour Report on Research Findings. https://www.beyondblue.org.au/docs/default-source/research-projectfiles/bw0185.pdf?sfvrsn=0 Accessed 6 March 2018 
21. Stewart, David W., et al. Focus Groups: Theory and Practice ( $2^{\text {nd }}$ edition), Thousand Oaks: SAGE Publications; 2007.

22. Lincoln YS, Guba EG. Naturalistic Inquiry. Beverly Hills, CA: Sage;1985.

23. Authors

24. Bradbury-Jones C, Breckenridge J, Clark MT, et al. The state of qualitative research in health and social science literature: A focused mapping review and synthesis. Int $J$ soc Res Miethiod. 2017;20(6):627-645

25. Braun V, Clark V. Using thematic analysis in psychology. Quai Res Psy hol. 2006;3(2):77101.

26. Gibbs G. Qualitative Data Analysis: Explorations with NVivo. Buckingham, Philadelphia: Open University Press; 2002.

27. Fennell K, Jarrett C, Kettler L, et al Watehing the bank balance build up then blow away and the rain clouds do the same: A thematic analysis of South Australian farmers' sources of stress during drought. J Rura' Stuc.'. 2016;46:102-110.

28. Alston M, Kent I. The Big Dry: The link between rural masculinities and poor health outcomes for rarming men. $J$ Sociol. 2008;44(2):133-147.

29. Viris H, Beil J. Saha S, et al. The mental health outcomes of drought: A systematic review aild callsal process diagram. Int J Environ Res Public Health. 2015;12(10):13251-13275.

30. Hanigan I, Butler C, Kokic P, et al. Suicide and drought in New South Wales, Australia, 1970-2007. Proc Natl Acad Sci USA. 2012;109(35):13950-5.

31. Guiney R. Farming suicides during the Victorian drought: 2001-2007. Aust J Rural Health. 2012;20(1):11-15. 
32. Powers J, Dobson A, Berry H, et al. Lack of association between drought and mental health in a cohort of 45-61 year old rural Australian women. Aust N Z J Public Health. 2015;39:518523.

33. O'Brien L, Berry H, Coleman C, et al. Drought as a mental health exposure. Environ Res 2014;131:181-187.

34. State of Queensland (2014) State of Queensland Agriculture Report. https://publications.qld.gov.au/storage/f/2014-07-02T05\%3A08\%3A03.2602/state-ofqueensland-agriculture-report-june-2014.pdf Published Jun 2014. Accessed 10 Dec 2017

35. Joiner T. Why people die by suicide. Cambridge, MA: Harvard Universicy Press; 2005.

36. Van Orden K, Cukrowicz K, Witte T, et al. The Interpersonal Theory of Suicide. Psychol Rev. 2010;117(2):575-600.

37. Stark C, Riordan V, Dougall N. Rurality and suicide. In: O'Connor R, Pirkis J, eds. The International Handbook of Suicide Prevention. $2^{\text {nd }}$ Ed. Chichester, West Sussex, UK; Hoboken: Wiley, Blackwell, 2016:713-733.

38. Authors

39. Fennell K, Hu1! M, Jones M, Dollman J. A comparison of barriers to accessing services for mental and physical health conditions in a sample of rural Australian adults. Rural Remote Hecilth. 2918; 18:4155.

40. Hull MJ, Fennell KM, Vallury K, Jones M, Dollman J. A comparison of barriers to mental health support- seeking among farming and non- farming adults in rural South Australia. Aust J Rural Health. 2017;25(6):347-353.

41. Brew B, Inder K, Allen J, Thomas M, Kelly B. The health and wellbeing of Australian farmers: A longitudinal cohort study. BMC Public Health. 2016;16(1):1-11. 
42. Ni Laoire C. 'A Matter of Life and Death? Men, Masculinities and Staying "Behind" in Rural Ireland', Sociologia Ruralis. 2001;41(2):220-36.

43. Moffatt J, Baker P. Farmers, mining and mental health: The impact on a farming community when a mine is proposed. Rural Society. 2013;23(1):60-73. 
Table 1. Focus group participants and suicide rates by geographical category (remoteness)

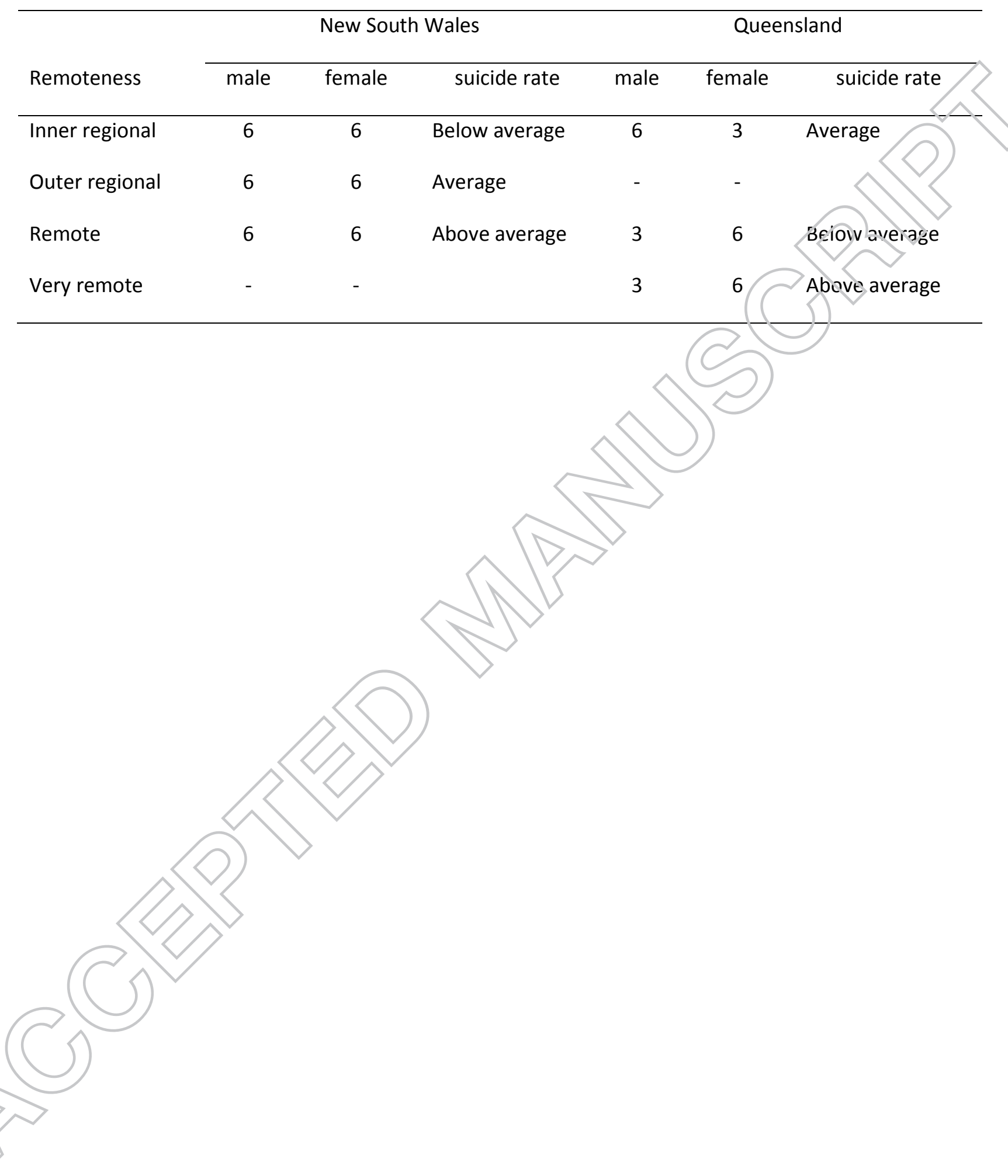


Appendix 1. Focus group questions

\section{ARC Farmers Suicide Focus Group Questions}

To explore main themes about participant attitudes towards suicide, perceived causes/risks, what may help or be possible protective factors and help-seeking.

1. What do you think might be some contributing factors or risks related to suicide?

2. What do you think might help people become less vulnerable and at risk? What are the possible protective factors that could alleviate hardship?

3. What are your/the community's attitudes toward suicide as an act (preventable?/predictable?/rational?)?

4. What are your/the community's attitudes toward help seeking?

\section{Questions and Focus Group format}

There will be at least 2 questions under each theme, 11 questions in total. Allowing 10 minutes per question each focus group will run for approximately 3 hours. The questions will take about 2 hours and discussion time either side will be allowed.

There will be a general introduction and discussion at the beginning, with participants reassured about the confidentiality of their responses and the availability of mental health support during or after the focys groups. An overview of the purpose of the study will be given, with an explanation of hov the session will run. Basic demographic information will be collected. Information about foliow-up mental health services both local and state-wide, will be distributed and discussed.

\section{Risk factors}

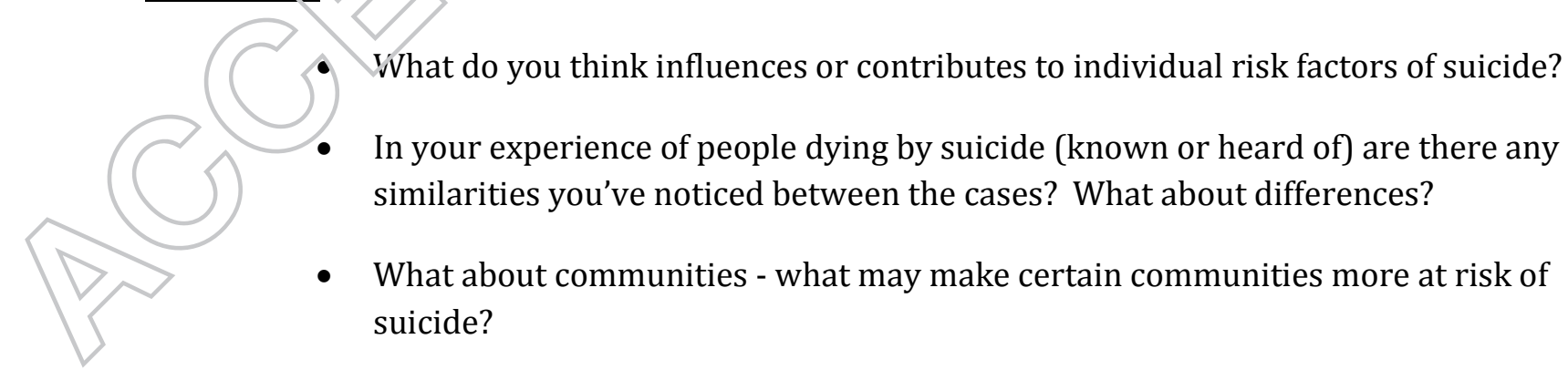

Protective factors

- What do you think could help someone who may experience suicidal thoughts? 
- What sorts of things have you heard of or have you experienced that may help protect an individual or community from suicide?

- What do you think helps certain communities be more resilient than others?

- What techniques or services or other types of help have you used, or others you know have used, when times have been tough, to help you pull through?

\section{Help seeking}

- Do you think you could recognise suicidal thoughts and behaviours if you or someone around you was thinking about suicide?

- What increases (or encourages) people to seek help if they are having probiems and/or thinking about suicide?

- What makes it difficult for people to seek help in your community?

- How could we improve people's knowledge of what services are available in their communities, and access to them? Do you think there are enough supports in your community, and are the supports that are available right for what people need? 